\title{
QUENCH HEATER STUDIES FOR THE LHC MAGNETS
}

\author{
F. Rodriguez-Mateos, F. Sonnemann \\ CERN, CH-1211 Geneva 23, Switzerland
}

\begin{abstract}
About 2000 LHC (CERN's Large Hadron Collider) superconducting magnets will be protected with quench heaters against development of excessive voltage and overheating after a resistive transition. The quench heater strips are powered by capacitor bank discharge power supplies. The strips are made of stainless steel partially plated with copper to reduce their resistance and to allow for the connection of quench heaters in series. The strips are embedded in between two polyimide foils. The initial power density and the current decay time determine the quench heater effectiveness.

Since only one type of heater power supply will be available, the copper plating cycle is adapted for the various magnet types to keep the resistance of the heater circuit constant. Different quench heater designs have been tested on various prototype magnets to optimise the copper-plating cycle and the electric insulation of the heater strip. This paper summarises the experimental results and computations that allowed to finalise the heater strip layout for all LHC magnets.
\end{abstract}

\section{INTRODUCTION}

\subsection{The Superconducting Magnets for LHC}

Within the superconducting magnet system for LHC, the following magnet types require active protection with quench heaters:

- 1232 twin-aperture dipole magnets (MB),

- the special dipole magnets for beam separation and recombination (MBX, MBRA, MBRB, MBRC)

- 392 twin-aperture main quadrupole magnets in the $\operatorname{arcs}(\mathrm{MQ})$,

- the twin-aperture quadrupole magnets in the dispersion suppressers and in the insertions (MQM family),

- $\quad$ the wide twin-aperture quadrupoles (MQY),

- the strong focusing quadrupoles of the inner triplets near the experiments (MQX).

Due to the high ultimate operating currents of these magnets (3.7-13kA), they store a significant amount of energy. Most of the magnets are powered in series (154 MB magnets, up to $51 \mathrm{MQ}$ magnets).

The protection of these magnets is ensured by firing the quench heaters since the natural quench propagation would not be sufficient to avoid overheating and excessive voltages in case of a resistive transition (quench). The fired quench heaters switch to the resistive state enough volume of superconducting cable such that the energy can be safely dissipated in the coils, keeping maximum temperatures and voltages within safe limits.
For the MB and MQ types, any quenching magnets are "de-coupled" from the other magnets in the circuit using a cold by-pass diode. The resistive voltage across the magnet provokes a fast commutation of the current from a quenching magnet to its parallel diode. The magnet chain is de-excited by opening switches across a dump resistor, in which the energy stored in the remaining superconducting magnets will be dissipated.

For the other magnet types, heaters are fired in all the magnets of the circuit if a quench is detected in any of them (or in a bus-bar or a superconducting current lead). Voltages and temperatures are kept below ultimate design limits and neither energy extraction nor "de-coupling" by cold by-pass diodes are necessary in these circuits.

\subsection{The Quench Heater Power Supplies}

The LHC standard heater power supply contains a bank with 6 capacitors $(4.7 \mathrm{mF} / 500 \mathrm{~V})$, where two sets of 3 parallel capacitors are connected in series, resulting in a total capacitance of $7.05 \mathrm{mF}$. The nominal operating voltage of the capacitors will be $U_{\text {nom }}= \pm 450 \mathrm{~V}$ with a mid connection to ground, giving a maximum stored energy of $2.86 \mathrm{~kJ}[1]$.

\section{QUENCH HEATER STRIPS}

\subsection{General Layout}

The quench heaters for the LHC magnets consist of one or two, $0.025 \mathrm{~mm}$-thick, austenitic stainless steel strips bonded in between two layers of polyimide electrical insulation foil. The latter acts as support and insulates the strips against the coils and the collar structure that is at ground potential. The thickness of each insulation foil is $0.075 \mathrm{~mm}$. A layer of $0.025 \mathrm{~mm}$ of epoxy glue is clad on the internal face of the polyimide foils for proper bonding to the strips during a warm rolling process. The quench heaters are subsequently creased in some cases to match the geometry of the coils of the magnet. They are then equipped with powering leads through soldered connecting elements. Once installed in a magnet, the heater strips are strongly compressed between superconducting coil and collars. Therefore, it is important that the austenitic stainless steel strips have smooth burr-free edges to avoid punching through the electrical insulation foil.

\subsection{Copper Plating}

It is sufficient to heat only some sections of the superconducting cable for protecting a magnet, since the quench propagates longitudinally into the non-heated 
sections (with typical velocities in the range of $15 \mathrm{~m} / \mathrm{s}$ to $20 \mathrm{~m} / \mathrm{s}$ at nominal current for the MB magnets). As an example, a $400 \mathrm{~mm}$-long section would be quenched in less than $10 \mathrm{~ms}$. Therefore, the austenitic steel strips are partially plated with copper, either on one or on both sides. This reduces considerably the voltage that needs to be applied during heater firing. The copper thickness is $0.004 \mathrm{~mm}$ and its "Residual Resistivity Ratio" (RRR) exceeds 30. The electrical resistance of the strips drops at $1.9 \mathrm{~K}$ according to the ratio between copper plated and non copper plated lengths.

\section{SIMULATION PROGRAMS}

The performance of the quench heaters is generally measured by means of the quench heater delay and the quench load as a function of applied magnet current. The quench heater delay is defined by the time interval in between firing of the heaters and observing the provoked quench. The quench load is given by the square of the current as a function of time integrated over time. When assuming adiabatic conditions, for a given magnetic field, this parameter is only a function of the hot spot temperature in the magnet coil.

Two simulation programs were developed to simulate the impact of quench heaters for the protection of main magnets.

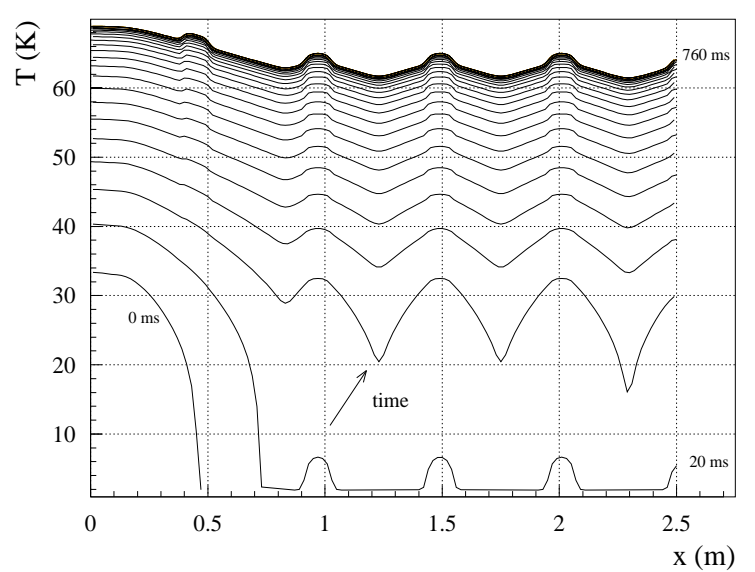

Fig. 1: Simulation result of a SPQR run. The figure shows the temperatures vs. longitudinal coordinate for a propagating original quench (from the left) and the impact of the fired quench heaters. A quench is first provoked where the heater strip is not copper plated.

The finite difference program SPQR numerically solves the heat balance equation including the cooling by helium and the heat transfer from the fired quench heater strip through the insulation layer into the superconducting magnet coil [2] [3]. The outcome of the simulation runs are quench parameters such as the longitudinal and transverse quench propagation velocity, the impact of eddy currents on the quench process, the hot spot temperature and the quench heater delay (see Figure 1).

In order to simulate the voltage and temperature development of a series of magnets the simulation package QUABER has been developed at CERN [4], which is based on the commercially available tool SABER $^{\text {TM* }}$. Among many other features, SABER ${ }^{\mathrm{TM}}$ allows the time transient simulation of any electrical circuit. The QUABER libraries contain the thermodynamic models that define the resistance development as a function of time for various parts of a magnet. They require quench parameters as input data that

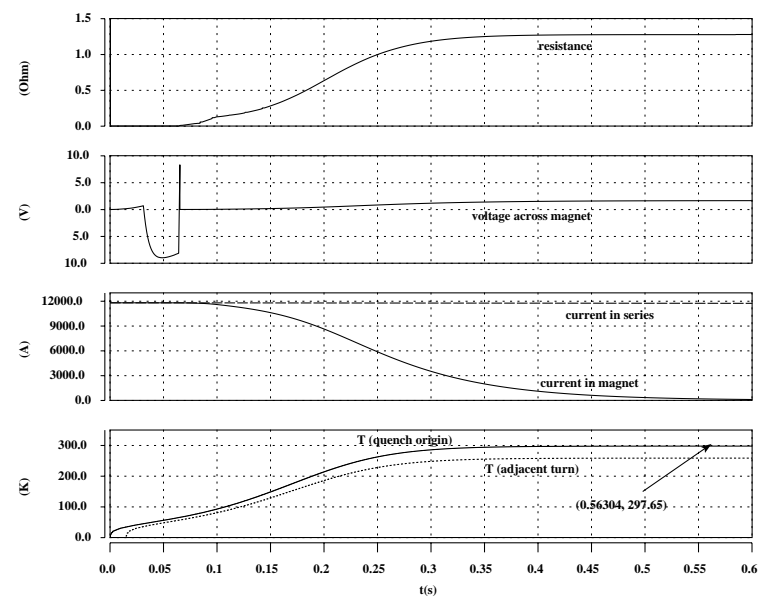

Fig. 2: A simulation result of a QUABER run. The figure shows the resistance growth, the voltage across the magnet, the current decay inside a quenching MB magnet and the hot spot temperature (assuming adiabatic conditions) as a function of time.

can be provided by experimental results or from SPQR simulations.

\section{RESULTS}

\subsection{Copper Plating}

A number of simulation studies have been carried out to define the number of required heater strips and to optimise the copper plating ratio [2,5] for the different LHC magnets. They resulted in a copper plating cycle of $120 \mathrm{~mm}$ non-copper plated and $400 \mathrm{~mm}$ copper plated for the main dipole magnets, which was confirmed by experimental results. As only one type of quench heater power supply will be installed in the LHC machine, it was decided to adjust the copper plating pattern of all the other magnets such as to keep the impedance of each quench heater circuit the same (a capacitance of $7.05 \mathrm{mF}$ and a resistance of around $11 \Omega$ at $1.9 \mathrm{~K}$ ). The outcome of these calculations is shown in Table 1.

${ }^{*}$ SABER is a Trademark of Analogy INC. 
Proceedings of the 2001 Particle Accelerator Conference, Chicago

\begin{tabular}{|c|c|c|c|c|c|c|}
\hline Magnet & Length & \multicolumn{2}{|c|}{ Pattern } & \multirow{2}{*}{$\begin{array}{c}\text { Width of } \\
\text { Stainless } \\
\text { Steel (SS) } \\
{[\mathrm{mm}]}\end{array}$} & \multirow{2}{*}{$\begin{array}{l}\begin{array}{l}\text { Number } \\
\text { of Strips } \\
\text { in Series }\end{array} \\
\text { (double } \\
\text { length) }\end{array}$} & \multirow{2}{*}{$\begin{array}{c}\begin{array}{c}\text { Number } \\
\text { of Heater } \\
\text { Power } \\
\text { Supplies }\end{array} \\
\text { (per } \\
\text { magnet) }\end{array}$} \\
\hline Name & {$[\mathrm{mm}]$} & $\mathrm{L}_{\mathrm{ss}}[\mathrm{mm}]$ & $\mathrm{L}_{\mathrm{Cu}}[\mathrm{mm}]$ & & & \\
\hline MB & 14358 & 120 & 400 & 15 & 1 & 4 \\
\hline MQ & 3100 & 120 & 320 & 15 & 4 & 2 \\
\hline MQMC & 2486 & 125 & 100 & 21 & 4 & 2 \\
\hline MQM & 3491 & 120 & 170 & 21 & 4 & 2 \\
\hline MQML & 4891 & 140 & 350 & 21 & 4 & 2 \\
\hline MQR & 3491 & 100 & 70 & 21 & 2 & 2 \\
\hline MQRL & 4891 & 120 & 125 & 21 & 2 & 2 \\
\hline MQY inner & 3508 & 130 & 190 & 21 & 4 & 2 \\
\hline MQY outer & 3508 & 100 & 250 & 15 & 4 & 2 \\
\hline MQXA & 6530 & 115 & 230 & 15 & 2 & 2 \\
\hline MQXB & 5714 & 120 & 215 & 15 & 2 & 2 \\
\hline MBRA,B,C & 9646 & 100 & 400 & 15 & 4 & 4 \\
\hline MBRS,MBX & 9646 & 100 & 200 & 15 & 2 & 2 \\
\hline
\end{tabular}

Table 1: Optimised heater strip layouts for the various LHC main magnets. The table also shows the number of heater circuits connected in series with each other and the number of quench heater power supplies per magnet.

\subsection{Insulation Layer}

The thickness of the insulation was changed in order to evaluate its impact on the quench heater delay. The simulation results indicated an exponential increase of the quench heater delay with a linear increase of the insulation layer thickness [1]. Experimental tests on a model dipole magnet with a different insulation layer thickness confirmed this tendency.

\section{QUENCH HEATER PRODUCTION: PRESENT STATUS}

The close collaboration between CERN and several European firms has demonstrated the feasibility of the industrialisation process, and 15-m long quench heaters (several hundreds of units) are being produced for the LHC pre-series MB magnets [6].

Quench heaters have also been produced for several prototypes MQXA and B magnets. Several short model magnets of MQM and MQY families are equipped with the protection elements as foreseen for the series units.

\section{CONCLUSIONS}

The list of key parameters of the quench heaters for all LHC magnets has been completed. The powering of the heater strips has been described. This has been used as an input to the final layout for the distribution of the quench protection equipment around the machine tunnel, which has been recently finalised at CERN.

\section{ACKNOWLEDGEMENTS}

The authors would like to thank Norbert Siegel and Tom Taylor for their continuous support. Thanks also to Rüdiger Schmidt for contributing with many ideas.
Specially acknowledged are the ones on reliability and machine operation issues.

F. Rodriguez-Mateos would like to express his gratitude to the firms which have participated in the development programmes concerning the industrialisation of the composite quench heaters.

\section{REFERENCES}

[1] F. Rodriguez-Mateos et al., "Quench Heater Experiments on the LHC Main Superconducting Magnets", EPAC 2000, Vienna, Austria

[2] F. Sonnemann and R. Schmidt, "Quench simulations of superconducting elements in the LHC accelerator", Cryogenics 40 (2000) p519-529.

[3] F. Sonnemann, "Resistive Transition and Protection of LHC Superconducting Cables and Magnets", PhD Thesis, University of Aachen, May 2001.

[4] D. Hagedorn and F. Rodriguez-Mateos, "Modelling of the quenching process in complex superconducting magnet systems", IEEE Trans. Magn. Vol 28, January 1992.

[5] A. Danner and F. Sonnemann, "Review of quench simulations for the protection of LHC main dipole magnets", CERN-ICP-IN-00-199, October 27, 1999.

[6] M. Modena et al., "Final Prototypes, First Pre-series Units and Steps towards Series Production of the LHC Main Dipoles", this conference. 